REGARDS

SUR LEECONOMIE ALLEMANDE

BULLETIN ECONOMIQUE DU CRAC

\section{Regards sur l'économie allemande}

Bulletin économique du CIRAC

72 | 2005

Varia

\title{
Industrie : les effets des relocalisations mondiales
}

\section{Isabelle Bourgeois}

\section{OpenEdition}

Journals

Édition électronique

URL : http://journals.openedition.org/rea/303

DOI : $10.4000 /$ rea.303

ISBN : 978-2-8218-0840-9

ISSN : 1965-0787

Éditeur

CIRAC

Édition imprimée

Date de publication : 1 juillet 2005

Pagination : 37

ISSN : 1156-8992

Référence électronique

Isabelle Bourgeois, "Industrie : les effets des relocalisations mondiales », Regards sur l'économie allemande [En ligne], 72 | juillet 2005, document 1, mis en ligne le 23 juin 2008, consulté le 15 septembre 2020. URL : http://journals.openedition.org/rea/303

Ce document a été généré automatiquement le 15 septembre 2020

(c) CIRAC 


\title{
Industrie : les effets des relocalisations mondiales
}

\author{
Isabelle Bourgeois
}

\section{Fin programmée de la production de produits blancs en RFA}

1 AEG (Nuremberg), Bosch Siemens Hausgeräte (Berlin-Spandau) et Miele (divers sites en Allemagne) ont annoncé au printemps vouloir fermer leurs unités de production ou réduire leurs effectifs outre-Rhin. La production de produits blancs n'est visiblement plus rentable en Allemagne. Non seulement le marché domestique est saturé, mais la concurrence des pays émergents fait aussi dramatiquement chuter les prix - les machines à laver de marque Beko (Turquie) ou les réfrigérateurs LG (Corée du Sud) se vendent aujourd'hui presque à $40 \%$ de moins qu'il y a cinq ans. Cette évolution réduit d'autant les perspectives des constructeurs nationaux (la marque historique allemande AEG avait été rachetée jadis par le suédois Electrolux) sur le marché de remplacement. A la saturation de ce segment de biens d'équipement de masse dans les pays industrialisés, comme à la montée en puissance des pays à bas salaires, s'ajoute aujourd'hui le renchérissement des prix de l'acier. Les constructeurs allemands de téléviseurs ont déjà fait les frais de cette nouvelle répartition du marché mondial, qu'on se rappelle seulement la longue agonie de Grundig, un des autres fleurons de l'histoire industrielle allemande.

Part des importations allemandes en provenance des pays à bas salaires (en \%)

\begin{tabular}{|l|c|c|}
\hline \multicolumn{2}{|c|}{$\begin{array}{c}\text { Part de la valeur totale des biens produits et importés } \\
\text { en RFA en } 2003\end{array}$} & $\begin{array}{c}\text { Evolution de la part des } \\
\text { importations }\end{array}$ \\
\hline Vêtements & 61 & \\
\hline
\end{tabular}




\begin{tabular}{|l|c|l|c|c|}
\hline Cuirs & 55 & & 2004 & 2015 \\
\hline \hline Ordinateurs & 42 & & & \\
\hline \hline Electronique & 33 & Chaussures & 98 & 98 \\
\hline Acier/sidérurgie & 16 & Téléviseurs & 77 & 90 \\
\hline \hline Automobile & 12 & Réfrigérateurs & 48 & $>80$ \\
\hline \hline Mesures et asservissement, mécanique de & 11 & Puces à mémoire & 35 & 60 \\
\hline précision & 10 & Canapés & & \\
\hline Caoutchouc et plasturgie & 9 & Volants (automobile) & 2 & 50 \\
\hline Agro-alimentaire & 9 & Véhicules & 8 & 21 \\
\hline Métallurgie & 8 & Moquettes & 50 \\
\hline Construction mécanique & revêtements & 15 & 20 \\
\hline Imprimerie & Papier & Sièges automobiles & 2 & 10 \\
\hline
\end{tabular}

Source : Frankfurter Allgemeine Zeitung (11-07-05). Pour 2003 : Boston Consulting Group (BCG)/ Destatis/FAZ. Pour 2004 et prévisions 2015 : BCG.

\section{Hausse de l'importation de produits manufacturés d'ici 2015}

2 La même évolution affecte un certain nombre d'autres secteurs industriels. La chaussure ou l'habillement se sont relocalisés au sein d'un marché mondial en reconfiguration, obéissant à l'impératif de la compression des coûts de production. Mais les coûts salariaux sont loin d'être le seul critère pour le choix d'un site. Car les choix de localisation sont bien plus souvent liés d'abord aux contraintes propres à chaque type d'activités industrielles. Pour la production de moquettes et autres revêtements de sol, par exemple, le critère premier est le calcul coût/avantage du transport de ces produits. Comme leurs propriétés physiques leur interdisent les longs voyages (ils se déforment, les fibres se cassent), ils doivent être produits au plus près du client final, en l'occurrence en Allemagne même. D'autres biens, comme les produits chimiques, se laissent tout aussi mal transporter. Mais comme l'industrie chimique est hautement concentrée, fortement internationalisée et soumise à une concurrence mondiale acharnée, elle sera quant à elle tentée de suivre ses grands clients lorsque ceux-ci se délocalisent. Pour avoir une vision prospective du marché en 2015, le groupe BASF avait commandé une étude au cabinet Boston Consulting Group, dont le quotidien 
Frankfurter Allgemeine Zeitung (11-07-05) a présenté quelques extraits. Il en ressort que la production d'un certain nombre de biens devrait émigrer d'ici une dizaine d'années vers les pays émergents. L'Allemagne importera alors presque la totalité de ses chaussures, téléviseurs ou réfrigérateurs.

INDEX

Mots-clés : délocalisation, importation, industrie 